\title{
The effect of different factors on intention to apply total quality management system in petroleum and liquefied gas enterprises in Vietnam: The role of the leader's personality
}

\author{
Truong Duc Thao and Duong Minh $\mathrm{Tu}^{\mathrm{a}}{ }^{*}$
}

${ }^{a}$ Dai Nam University, Hanoi, Vietnam

\begin{tabular}{l}
\hline C H R O N I C L E \\
\hline Article history: \\
Received April 8, 2021 \\
Received in revised format May \\
29,2021 \\
Accepted July 152021 \\
Available online \\
July 152021 \\
\hline Keywords: \\
TQM \\
Application intention \\
Quality management \\
Petroleum and liquefied gas \\
business in Vietnam \\
\hline
\end{tabular}

\begin{abstract}
A B S T R A C T
This study was conducted based on Davis's extended technology acceptance model (TAM) (1989) and survey data of 486 petroleum and liquefied gas enterprises in Vietnam on their intention to apply using a total quality management (TQM) system. Research results show that factors such as (1) Perception of the effectiveness of TQM; (2) Perception of the effectiveness of the convenience in using TQM; and (3) Perception of the effectiveness of TQM compared to the old system which has a positive impact on the intention to apply the total quality management system in petroleum and liquefied petroleum gas enterprises in Vietnam. Besides, the perception of decision-makers on issues related to quality management in these enterprises also has a direct influence on the perception of the TQM usability and indirect effect of the intention to use TQM application in these enterprises.
\end{abstract}

(C) 2021 Growing Science Ltd. All rights reserved.

\section{Introduction}

According to data from the Vietnam Chamber of Commerce and Industry (VCCI), up to December 31, 2019, the country has 758,610 operating enterprises, of which small and medium enterprises (SMEs) account for over 95\%. For quality management issues, Vietnamese enterprises currently apply the ISO quality management standard system and this system is also totally suitable for small and medium enterprises. However, in the long term, businesses also need to consider perfecting their quality management system with a total quality management system (TQM). In Vietnam, the petroleum and liquefied gas market, although newly formed since the early $1990 \mathrm{~s}$, has made significant changes and tended to increase rapidly in the past 10 years. Vietnam's petroleum and liquefied petroleum gas market still has many related issues including market demand; current situation of domestic petroleum and liquefied gas production; the import and export business of petroleum and gasification liquid; the situation of organization of retail distribution as well as the situation of illegal gas extraction in the market, along with the State's management activities for this conditional business line. To solve the above problems, several solutions have been proposed, such as emerging the application of quality management systems such as ISO9000 or Total Quality Management (TQM). Although total quality management TQM has been applied for many years now in many countries around the world such as in European countries, the US, Japan, etc., but in Vietnam, the application of TQM in businesses has only begun to receive attention in the last few years.

Research on TQM applications often goes in two directions, namely the impact of TQM on enterprise activities (TQM output) and factors affecting effective TQM application (TQM input). These two research directions are based on the same assumption that enterprises and organizations have already applied TQM. Previous studies did not consider the factors affecting the acceptance of the use of TQM by an enterprise or organization. Meanwhile, the acceptance of TQM usability is a prerequisite for researchers to consider how to apply TQM effectively and how TQM will positively affect the activities of such enterprises

* Corresponding author Tel.: +84 982130786

E-mail address: tudm@dainam.edu.vn (D. M. Tu)

(C) 2021 Growing Science Ltd. All rights reserved.

doi: $10.5267 /$ j.uscm.2021.7.006 
and organizations. Studies on new system acceptance, using Davis's (1989) TAM technology acceptance model, seem to forget the comparison with the existing old system. According to the author, there are quite a few studies that refer to comparing the effectiveness of the old system with the new system, although the new system is effective, it is clear that businesses and organizations when deciding to When they decide to adopt a new system, they have to compare the new system with the old one, and they only accept the new system when they feel that the new system is superior to the old system. There are quite a few studies to expand the TAM model by adding new factors, but the factors that are specific to Vietnamese economy and culture do not seem to have paid attention to, including the perception of being a traditional person and a modern person, even though self-perception is a factor that has been confirmed to have a strong impact on people's decisions, and shows a tendency whether to easily accept new things. This is the factor that the authors predict to supplement the TAM model well in studies not only on the acceptance of TQM systems but also in other studies.

From the above theoretical and practical issues, we conducted a study on some factors affecting the intention to apply a total quality management system (TQM) in petroleum and gasification enterprises in Vietnam to provide a basis for promoting the application of TQM in product quality management in these enterprises.

\section{Research overview and theoretical basis}

\subsection{Studies on $T Q M$}

\subsubsection{Research on the influence and role of TQM on business activities}

The authors of this research, often focus on emphasizing the role of TQM in improving the efficiency of agencies and organizations around the world, such as public hospitals in Wales (Potter, Morgan, \& Thompson, 1994); companies (64 companies in the 1,000 largest) in Taiwan (Huarng \& Chen, 2002); 359 companies in the US (Ahire, Waller, \& Golhar, 1996). Studies can also be directed towards comparing the effectiveness of TQM application among companies that apply and do not apply TQM, with effective and ineffective application of TQM. Specifically, the more rigorously companies apply TQM standards, the higher the quality effect of the company's products (Ahire et al., 1996). Still in this topic, several other studies have gone into depth and detail into the components of TQM and examined the extent to which these components affect the performance of enterprises. The application of TQM can be divided into two parts: hardware and software. Hardware is included in the regulations, technical tools of TQM, such as statistical process control, Pareto chart, etc. The part of human resource training that contributes to the development of human resources of the organization applying TQM is provided software of TQM. These two main components of TQM have different effects on firm performance (Rahman \& Bullock, 2005). Adopting TQM will significantly improve employee role ambiguity, job satisfaction, job engagement, organizational commitment, and employee job change intentions. On the other hand, TQM does not significantly affect the role conflict, task characteristics and job satisfaction of employees (Guimaraes, 1996); and customer satisfaction (Peters, 1988; Schonberger, 1994). In addition to studies on the role of TQM in enterprises, several studies focus on studying the conditions for applying TQM in organizations, these studies indicate success or failure in the application of TQM, in particular.

\subsubsection{Research on factors affecting the application of TQM in enterprises}

TQM is most effective only when adopted by companies, formally and long-term (Ahire et al., 1996). These studies seek to answer the questions, what factors make TQM successful? What is the relationship of the important factors that create success in the practice of TQM? (Huarng \& Chen, 2002). The ineffective application of TQM leads to a waste not only of finance but also of time and effort. The cause of such failure could be (1) half-hearted implementation of TQM (Ahire et al., 1996); (2) objections from middle management, disagreement among employees, inappropriate training program design (Edwards \& Sohal, 2003); (3) the ability of managers to understand and communicate about effectiveness, which is the reason for applying TQM (Beer, 2003). Context factors have also been studied by researchers in the direction of factors affecting the ability to apply TQM effectively, company origin, company size, national or global company to the ability to apply TQM effectively (Sila, 2007). Collectively, studies are often based on companies that have already decided to adopt TQM, with the implicit assumption that a TQM system will work for companies that apply it with a lot of research. Research supports this (Flynn, Schroeder, \& Sakakibara, 1995; M.Terziovski \& D.Power, 2007; Powell, 1995). After that, the authors only focus on studying the factors affecting the effective application of TQM. Meanwhile, it is surprising that the research on the factors influencing a firm's decision to adopt TQM is still rather modest, although before firms consider adopting TQM effectively, they are faced with the question of whether to use the system or not. Especially in the context of businesses doing business in the petroleum and liquefied petroleum gas industry in Vietnam, when the quality of products in this industry has many problems about counterfeit goods, counterfeit goods, fire safety, etc.

\subsection{Theoretical basis}

\subsubsection{Theoretical framework for system acceptance}

As concluded above, the studies on TQM are mainly in two directions, namely the role of TQM and the conditions to apply TQM, while very few studies discuss the intention to apply TQM in enterprises. It can be said that one of the famous theories 
and has been applied by many researchers recently in topics related to accepting new things of both individuals and organizations is the acceptance model technology (TAM) of (Davis, 1989). Technology acceptance model is a new theory developed based on rational behavior theory, built in 1975 by Fishbein and Ajzen, to explain any human behavior in general, including behavioral acceptance (Ajzen, 1991).

Model of rational behavior: According to Fishbein and Ajzen, human behavior starts from the person's attitude to that behavior, it is expressed by people's approval of the behavior. After people have a positive attitude to support a certain behavior, they will consider additional factors such as pressure from society, from relatives around them, through whether society, their relatives support them. This support or disapproval is called a subjective norm. The impact of attitudes and subjective norms will create a person's intention to perform a behavior, expressed by the plan or ability of someone, in a certain context, to perform a behavior. So the intention to perform a behavior is the factor that best explains someone's behavior (Ajzen, 1991).

Technology Acceptance Model: Both TPB (an extension of TRA) and TAM explain intention to adopt online learning systems, but the TAM model explains better than TPB (Ndubisi, 2006). Therefore, inheriting from the TRA model, Davis has developed a technology acceptance model to explain whether a person or an organization accepts a certain system (Tang, Chen, \& Wu, 2010). The first model that Davis proposed is still based on the TRA model, according to which the behavior of accepting a new system of an organization or individual is still largely influenced by the intention to accept that system. The intention to accept the system is then in turn influenced by the attitude towards that system (Davis, 1989). Two important components that Davis added in the TRA model to translate into the technology acceptance model are the perceived system efficiency and the perceived ease of use of the system. According to Davis, System Efficiency Perception is the degree to which a person believes that using a particular system will improve his or her job performance, while Ease of Use Perception is the degree to which a person believes that using a particular system should be effortless (Davis, 1989). When people perceive a system as effective for their work, they tend to have a positive attitude towards using that system. Similarly, when people perceive a system as easy to use, they will have a positive attitude in favor of using that system (Davis, 1989).

After many revisions, the final technology acceptance model (TAM) was proposed by Davis and associates. In this model, the attitude factor towards using the system was no longer included in the model (Venkatesh \& Davis, 1996). Accordingly, the perceived effectiveness of the system and the perceived ease of use of the system directly affect the intention to use the system. In addition, the authors have also predicted that there will be several variables affecting the perceived effectiveness and perceived ease of use of the system. From this model, other researchers have suggested an extended model of the technology acceptance model with four main development directions including: contextual factors; external factors affecting the perception of "system performance" and the perceived ease of use of the system; elements from other theories; and using other measurement tools (Marangunić \& Granić, 2015). Over time, the application of the technology acceptance model has shown that it is a relatively flexible model and has been applied by research in a wide range of fields, from individual decisions to organizational decisions (Mortensona \& Vidgen, 2016).

\subsubsection{Enterprise TQM Application Intent}

In their research, Terziovski and Power (2007) identified that the TQM application of enterprises needs to be viewed from the perspective of a change management process. There are many businesses, business leaders realize that, in order to improve competitiveness, change is required (Oakland, 2004). To perceive and apply change in management, especially the application of TQM in enterprises, it is necessary to clearly identify which factors, including positive and negative factors, affect the process of changing. The application of TQM in the enterprise requires a clear plan, a coherent strategy and all processes in the enterprise need to relate to each other and must be continuously improved.

The system acceptance model (TAM) was developed by Davis based on the rational behavior model (TRA) of Fishbein and Ajzen. In which, the factor of intention to accept the system is maintained by Davis in terms of meaning and role as in the rational behavior model (Venkatesh \& Davis, 1996). According to Fishbein and Ajzen, intention is the degree to which a person is willing to try to perform a behavior, as a general rule, higher intention corresponds to higher ability to perform the behavior (Ajzen, 1991). Thus, the concept of intention to adopt a total quality management system, in this study, is defined as the degree to which an individual is willing and intends to make an effort to apply the management system. value total quality into your organization. Therefore, the concept of intention to adopt a total quality management system (TQM) is understood as the degree to which an individual is willing and intends to make efforts to apply the management system value total quality into your organization.

\subsubsection{Factors affecting the intention to apply TQM in enterprises}

\subsubsection{Feelings about the efficiency of the system}

According to Davis, the degree to which an individual or organization accepts the application of a certain system or technology is influenced by how much that individual or organization perceives the effectiveness of that system. This perception may not be so tied to the individual's or the organization's understanding of the system as in the case of a new and unfamiliar system (Venkatesh \& Davis, 1996). In his research, Davis (1989) defines perceived system effectiveness as "the degree to which an 
individual believes that using a certain system will increase his or her job performance". The perception of the effectiveness of the system affects the intention of an organization or individual to accept the system, from the perspective that the system has not been used and is in front of the ability to be accepted, the effectiveness of the system will be determined. The present system has the meaning of the future. For the current system in use, the perception of the actual performance of the system will influence the intention to continue using the system. Similarly, for the selection of a replacement system, comparing the perceived performance of the new system with the actual performance of the old system will influence the intention to continue using the old system or to replace it with a new one (Xu \& Quaddus, 2007). Based on this concept of Davis, the author gives the perceived experience of the effectiveness of the "comprehensive quality management system" as follows: Perceived effectiveness of the total quality management system is the level of degree to which an individual or organization believes that the use of a total quality management system in an organization will increase the effectiveness of that organization's quality management. Thus, Perception of the effectiveness of a new technology or management and Perception of the effectiveness of a new technology or a new way of management compared to existing technology will be factors influencing the intention application of TQM in the enterprise.

\subsubsection{Perception of the ease of system using}

Research by Elbeltagi et al. (2005) emphasizes that perception of the ease of system use positively influences the acceptance of individuals to use decision support systems in Greece local government agencies (Elbeltagi, McBride, \& Hardaker, 2005). Accordingly, when an individual feels the decision support system is easy to use, they will be more inclined to accept and use the decision support system. With systems in general and new systems in particular, the easy application of the system, in other words, the ease of use of the system, will greatly affect the success of an organization or individual that applies the system (Venkatesh \& Davis, 1996). According to Davis, perception of ease of use is the degree to which an individual believes that using a system is easy and effortless (Davis, 1989). Therefore, in this study, the author defines perceived ease of use of the total quality management system as the degree to which an individual or organization believes that the application of the total quality management system is easy and effortless. It can be concluded that the perceived ease of use affects the intention to apply TQM in enterprises. However, the perception of ease of use depends on the perception of the decision maker himself. The sense of self comes from the idea that we all have visions of what we want, of what we really are. Self-perception varies across cultures and influences intrinsic factors such as motivation to perform or perceived performance (Markus \& Wurf, 1987). According to (Mai, Kwon, Lantz, \& Loeb, 2003), people who perceive themselves as modern tend to be more open to change, more likely to be pioneers in shopping, choosing, accepting newer products and systems than traditional people, and they are often younger and more educated, etc.

\section{Research models, scales and data}

\subsection{Research models}

From the theoretical overview of the factors affecting the intention to apply TQM, we propose a research model on this issue as follows:

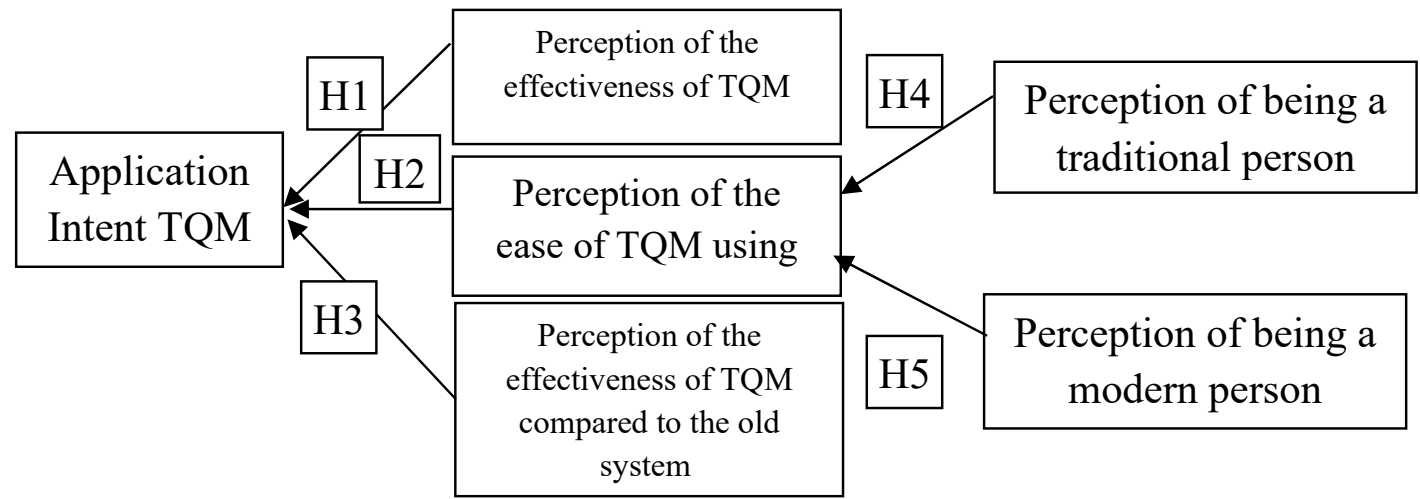

Fig. 1. Research model of TQM application intention

Based on this research model, we propose the following hypotheses:

$\mathbf{H}_{1}$ : Perceived effectiveness of TQM has a positive impact on the intention to apply TQM in petroleum and liquefied petroleum gas enterprises in Vietnam.

H2: Perceived ease of use of TQM has a positive impact on the intention to apply TQM in petroleum and liquefied petroleum gas enterprises in Vietnam.

H3: Perceived effectiveness of TQM compared to the old system has a positive impact on the intention to apply TQM in petroleum and liquefied petroleum gas enterprises in Vietnam.

$\mathbf{H}_{4}$ : The perception of being a traditional leader has a negative impact on the perception of the ease of use of TQM in petroleum and liquefied petroleum gas enterprises in Vietnam. 
H5: A leader's perception of himself as a modern person has a positive effect on the perception of ease of use of TQM in petroleum and liquefied petroleum gas enterprises in Vietnam.

\subsection{Scales used in the study}

Scales, Perception of the effectiveness of TQM (06 observed variables); Perception of the ease of use of TQM ( 07 observed variables); the perception of the effectiveness of TQM compared to the old system (06 observed variables) is inherited from the study of Davis (1989). The scales of self-perception, Perception of being a traditional person (05 observed variables); Perception of being a modern person (05 observed variables) is inherited from Mai et al. (2009). The applied intention scale TQM with 03 observed variables is inherited in the study of Ong et al. (2017).

\subsection{Research data}

The study mainly uses primary data based on the survey of 486 petroleum and liquefied petroleum gas enterprises in Vietnam about the intention to apply TQM in quality management in enterprises. The sample size is calculated according to the sampling formula of Hair et al. (1998), in which, with the total number of survey propositions of 32 questions, the minimum required number of survey samples is 160 votes or better 320 valid votes. We have distributed 600 questionnaires to 600 petroleum and liquefied petroleum gas enterprises in Vietnam by means of non-probability random sampling and asked questions on the subjects who are directly in charge of quality management in Vietnam in person or by email between October 2020 and February 2021. As a result, 508 questionnaires were collected in two forms: direct responses by filling in pre-printed questionnaires and via email, of which 22 questionnaires were invalid due to incomplete information or respondents were not the person in charge of quality management of the enterprise, remaining 486 valid votes were used for the analysis of this study. Thus, with 486 valid questionnaires used in the study, the sample size of the study satisfied the conditions to conduct exploratory factor analysis EFA, confirmatory factor analysis CFA, model estimation by means of exploratory factor analysis. SEM linear structure process and is highly representative to ensure reliable research results. EFA analysis results with Principal factoring method with Promax rotation and breakpoint when extracting factors with eigenvalue equal to 1 used for factor analysis with 32 important variables The results showed that the KMO coefficient reached 0.882 with the Sig value. $=$ 0.000 and Eigenvalues reached 69,411 at the factor stop of 1.38 . The results of the rotation matrix also show that the research scales converge on 06 factors in accordance with the proposed theoretical research model. The results of testing the reliability of the concepts and research scales show that the Cronbach's Alpha coefficients of the factors all reach values greater than 0.7 , so the scales used in the study are appropriate. The results of CFA confirmatory factor analysis for these scales have 447 degrees of freedom $(\mathrm{df}=447)$. The results of the CFA test show that the model is compatible with the research data set: Chisquare $=989,778(\mathrm{p}=000) ; \mathrm{cmin} / \mathrm{df}=2.214 ; \mathrm{GFI}=0.889 ; \mathrm{TLI}=0.940 ; \mathrm{CFI}=0.946 ;$ and $\mathrm{RMSEA}=0.05$. The normalized weights of the observed variables are all greater than 0.5 and the unnormalized weights of the variables are statistically significant, so the convergence value of the scales can be confirmed. The correlation coefficients of the concepts are all less than one unit, so the concepts gain discriminant value. The measurement model is suitable for the research data set, there is no correlation between the measurement errors, so the unitarity is achieved. Thus, the research data set satisfies the conditions to include in testing the linear structural model on the relationship of the intention to apply TQM and the factors affecting the intention to apply TQM in petroleum and liquefied petroleum gas trading in Vietnam.

\section{Results and discussion}

\subsection{The results of model testing by linear structural equation (SEM)}

The test results of the critical model have 451 degrees of freedom $(\mathrm{df}=451)$. SEM test results show that the model achieves the compatibility with the research data set with the values, Chi-square $=1020,278(\mathrm{p}=000) ; \mathrm{cmin} / \mathrm{df}=2.262 ; \mathrm{GFI}=0.886$; $\mathrm{TLI}=0.938 ; \mathrm{CFI}=0.943$; and RMSEA $=0.051$. The impact of factors affecting the intention to apply TQM in petroleum and liquefied petroleum gas enterprises in Vietnam has the estimated results of the model for the value R2 $=0.304$, that is, 30.4 $\%$ change of intention to apply TQM in petroleum and liquefied petroleum gas enterprises in Vietnam is influenced by the factors in the model. In particular, the factor "Perception of the effectiveness of TQM compared to the old system" has the strongest impact on "the intention to apply TQM in petroleum and liquefied petroleum gas enterprises in Vietnam" with the system. standardized Beta number is 0.389 and at $99 \%$ significance level $\left(\mathrm{P}_{-}\right.$value $\left.=0.000\right)$; followed by the factor "Perception of the ease of use of TQM" with standardized Beta coefficient of 0.289 and at $99 \%$ statistical significance ( $\mathrm{P}$ _value $=0.000$ ); the last factor is "Perception of effectiveness of TQM" with standardized Beta coefficient of 0.215 and at $99 \%$ statistical significance $\left(\mathrm{P}_{-}\right.$value $\left.=0.000\right)$. On the other hand, when considering the impact of the factors that perceive themselves as traditional or modern people of leaders in petroleum and liquefied petroleum gas enterprises in Vietnam, how they affect the "feel of perceived ease of use of TQM" gives the result, R12 $=0.305$, that is, $30.5 \%$ of the change in "Perception of TQM's ease of use" is explained by the user's own perception. Management is responsible for decision making on quality management issues. If the leader responsible for making decisions on quality management issues at a petroleum and liquefied gas trading enterprise in Vietnam perceives himself as a modern person, it will have a positive impact on the "perception of the ease of using TQM" with a standardized Beta coefficient of 0.487 and at $99 \%$ statistical significance ( $\left.P \_v a l u e=0.000\right)$. However, if the leader responsible for decision-making on quality management issues at a petroleum and liquefied petroleum gas enterprise in Vietnam perceives himself as a traditional person, it will negatively affect the "perception of the ease of using TQM" with a standardized Beta coefficient $(-0.230)$ and at $99 \%$ statistical significance $\left(P_{-}\right.$value $\left.=0.000\right)$. 
The estimated results of the main parameters in the theoretical model are presented in the table below. The estimated results show that all hypotheses $\mathrm{H}_{1}, \mathrm{H}_{2}, \mathrm{H}_{3}$ and $\mathrm{H}_{4}$ and $\mathrm{H}_{5}$ are accepted with statistical significance reaching over $99 \% \%$. Specifically:

Table 1

Normalized model estimation (SEM) results

No. Relationships between concepts $\begin{array}{ccc}\text { Normalized } & \text { Unnormalized } & \text { Standard } \\ \text { Estimation } & \text { estimate } & \text { Deviation }\end{array}$

R2 of intention to apply TQM in petroleum and liquefied petroleum gas enterprises in Vietnam =0.304

\begin{tabular}{|c|c|c|c|c|c|c|c|c|}
\hline 1 & Int & $\leftarrow$ & Easy & 0.289 & 0.396 & 0.063 & 6.247 & 0.000 \\
\hline 2 & Int & $\leftarrow$ & Eff & 0.215 & 0.322 & 0.070 & 4.639 & 0.000 \\
\hline 3 & Int & $\leftarrow$ & EffCom & 0.389 & 0.564 & 0.070 & 8.092 & 0.000 \\
\hline \multicolumn{9}{|c|}{ R12 of Perceived ease of use of TQM in petroleum and liquefied petroleum gas enterprises in Vietnam $=0.305$} \\
\hline 5 & Easy & $\leftarrow$ & MS & 0.487 & 0.427 & 0.040 & 10.664 & 0.000 \\
\hline 6 & Easy & $\leftarrow$ & TS & -0.230 & -0.138 & 0.027 & -5.108 & 0.000 \\
\hline
\end{tabular}

The results of the study are presented in the form of a model as follows:

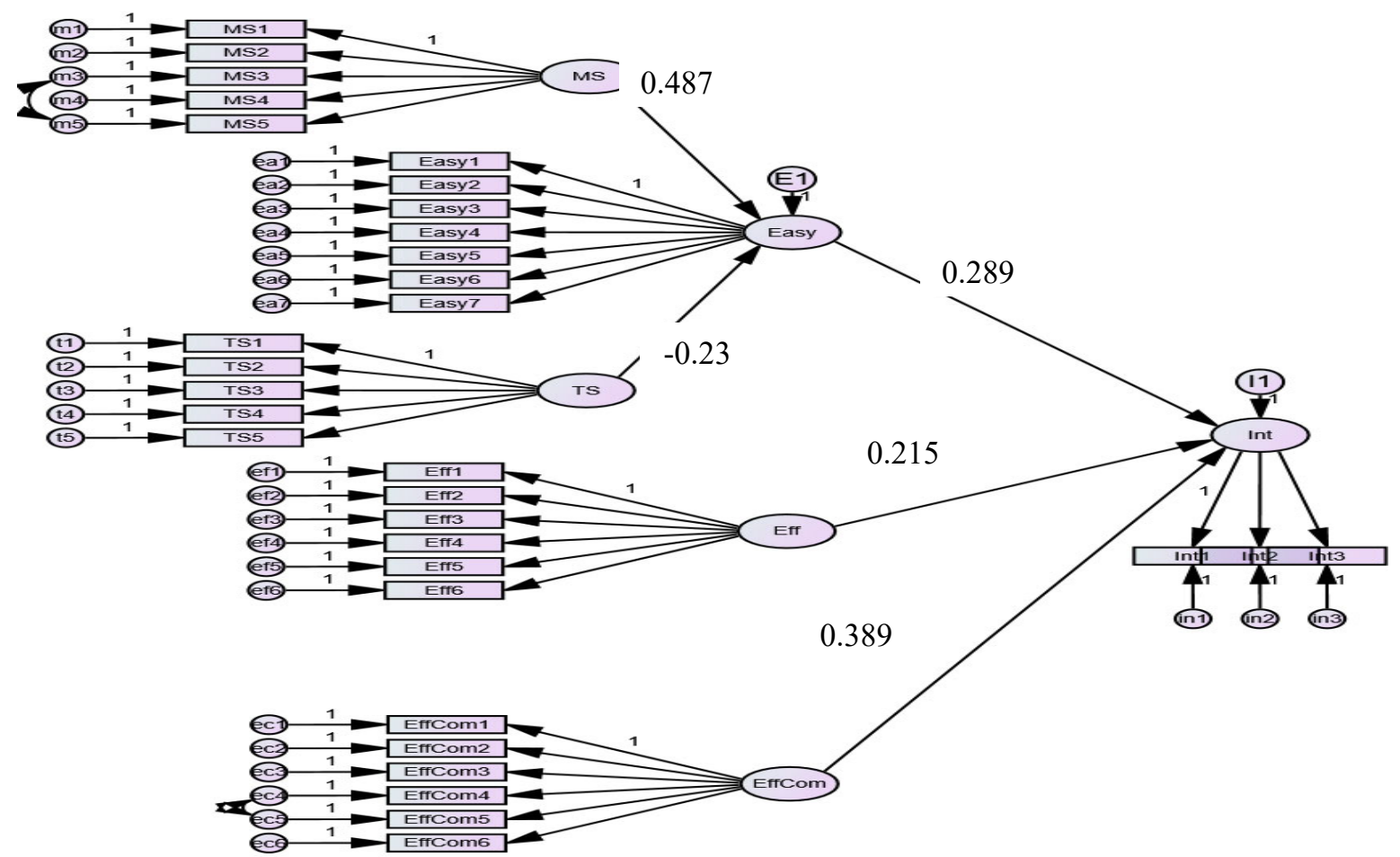

(Source: Calculation results from the linear structural model)

\subsection{Discussion}

Fig. 1. Theoretical model test results

From the estimated results of the research model, we make the following comments:

Firstly: The effect of perceived effectiveness of TQM on intention to apply, the results of this study support the studies of authors such as the study of Hong and associate 2014 on 497 university students in Hong Kong about the intention to use the research information system, the standardized coefficient $\beta$ is $0.280 \mathrm{p}<0.001$; Research by Tang and associate 2010 on the intention to participate in the TQM quality management system of Chinese workers, the standardized $\beta$ coefficient of indirect impact through attitude is $0.254 \mathrm{p}<0.01$; Research by Rehman and associate 2019 on the intention to buy online in Pakistan, the normalized $\beta$ coefficient is $0.260 \mathrm{t}=2.32 \mathrm{p}<0.01 \ldots$ This result shows that the decision of a business to adopt a new quality system is highly dependent on the effectiveness of the system itself. When decision-makers feel the effectiveness of the TQM system, they feel that TQM will help their business' operations operate effectively, achieve sales and customer satisfaction goals.

Secondly, the effect of the perceived effectiveness of TQM compared with the old system on the intention to apply TQM in business. This result supports the studies of authors such as: Research by Brezavšček et al. (2014) on intention to use SPSS 
in social science research of Slovenian students, standardized $\beta$ coefficient is $0.643 \mathrm{p}<0.001$; Slatten's 2012 study on the intention to pursue certifications of 248 nonprofit organizations in Louisiana, standardized $\beta$ coefficient $0.701 \mathrm{p}<0.001$. In other words, businesses, represented by decision makers, are very interested in not only the effectiveness of the TQM system in general, but also the effectiveness of TQM compared to the existing quality management system.

Thirdly, the effect of perceived ease of use of TQM on the intention to use. This result supports the studies of the authors such as: the study of Brezavšček and associate 2014 on intention to use SPSS in social science research of Slovenian students with standardized $\beta$ coefficient is $0.618 \mathrm{p}<0.001$; Research by Hong and associate 2014 on 497 university students in Hong Kong on the intention to use research information system with the standardized $\beta$ coefficient is $0.30 \mathrm{p}<0.001$. Each enterprise is a collective, a system consisting of many parts, many people, they have different demographic characteristics, such as: different age, different personality, education level. Meanwhile, TQM is a comprehensive quality management system that requires all individuals in the organization to participate. Therefore, the ease of use of the system plays an important role in determining whether the application of the system is really effective.

Fourthly, the influence of self-perception on the perception of ease of use of TQM, the test results have given the value ( $P_{\text {_value }}$ ) of Perception as a traditional person and Perception as a modern person. great $=0.000$ and $=0.000$ are both $<0.05$, respectively, $\mathrm{t}$ is equal to $=-5.108$ and $=10.664$, respectively. This result is consistent with the expectation that both these variables have an influence on the perception of the ease of use of TQM, in which the perception of the traditional self has a negative effect, the opposite is the perception of self modern people with positive influence. The standardized $\beta$ coefficient of the factor Perception of being a modern person $=0.487$, confirming that this is the factor which not only affects, but also has the strongest influence on, the perception of ease of use of TQM, of other users. decision makers about the application of the quality management system in the enterprise. Ranked second in terms of influence and from the opposite perspective is the factor Perceiving yourself as a traditional person with standardized $\beta$ coefficient $=-0.23$. Thus, it can be affirmed that the self-perception factor plays an important role in influencing an individual's perception of the ease of TQM application, thereby indirectly affecting the intention to apply TQM in its business.

\section{Some recommendations to state management agencies to promote the intention to apply TQM in petroleum and liquefied petroleum gas enterprises in Vietnam}

There should be stricter legal corridors in managing conditional business activities of the petroleum and liquefied petroleum gas industry.

Encourage liquefied petroleum gas enterprises to apply advanced quality management systems to their production and business activities.

Support and promote the promotion of petroleum and liquefied petroleum gas enterprises to apply and effectively apply the quality management system in their production and business activities, in order to create a spillover effect in the community, recommend consumer to support enterprises which apply quality management systems.

Support enterprises in consulting, transferring and applying quality management systems in general and TQM in particular in promoting and introducing to petroleum and liquefied petroleum gas enterprises in particular and other enterprises in general.

Review the training of employees and quality management at universities, providing training guidance and consulting in a direction that is more closely related to reality. There may be support policies for students studying this field both in Vietnam and abroad.

\section{References}

Ahire, S. L., Waller, M. A., \& Golhar, D. Y. (1996). Quality management in TQM versus non-TQM firms: an empirical investigation. International Journal of Quality \& Reliability Management, 13(8), 20.

Ajzen, I. (1991). The theory of planned behaviour. Organizational behaviour and human decision processes, 50(2), $179-211$.

Beer, M. (2003). Why Total Quality Management Programs Do Not Persist: The Role of Management Quality and Implications for Leading a TQM Transformation. Decision Sciences, 34(4), 20.

Davis. (1989). Perceived usefulness, perceived ease of use, and user acceptance of information technology. MIS quarterly, 13(3), 319-339.

Edwards, R., \& Sohal, A. S. (2003). The human side of introducing total quality management: Two case studies from Australia. International Journal of Manpower, 24(5), 17.

Elbeltagi, I., McBride, N., \& Hardaker, G. (2005). Evaluating the Factors Affecting DSS Usage by Senior Managers in Local Authorities in Egypt. Journal of Global Information Management, 13(2), 24.

Flynn, B. B., Schroeder, R. G., \& Sakakibara, S. (1995). The Impact of quality management practices on performance and competitive advantage. Decision Sciences, 26(5), 659-691.

Guimaraes, T. (1996). TQM's impact on employee attitudes. The TQM Magazine, 8(1), 6.

Huarng, F., \& Chen, Y.-T. (2002). Relationships of TQM philosophy, methods and performance: a survey in Taiwan Industrial Management \& Data Systems, 102(3/4), 9. 
Mai, N. T. T., Kwon, J., Lantz, G., \& Loeb, S. G. (2003). An Exploratory Investigation into Impulse Buying Behavior in a Transitional Economy: A Study of Urban Consumers in Vietnam. Journal of International Marketing, 11(2), 23.

Marangunić, N., \& Granić, A. (2015). Technology acceptance model: a literature review from 1986 to 2013. Universal Access in the Information Society, 14(1), 15.

Markus, H., \& Wurf, E. (1987). The dynamic self-concept: A social psychological perspective. Annual review of psychology, $38,39$.

Mortensona, M. J., \& Vidgen, R. (2016). A computational literature review of the technology acceptance model. International Journal of Information Management, 36, 12.

Ndubisi, N. O. (2006). Factors of Online Learning Adoption: A Comparative Juxtaposition of the Theory of Planned Behaviour and the Technology Acceptance Model. International Journal on ELearning, 5(4), 21.

Oakland, J. (2004). Oakland on Quality Management: Butterworth-Heinemann.

Peters, T. (1988). Facing up to the need for a management revolution. California Management Review, $30(2), 31$.

Potter, C., Morgan, P., \& Thompson, A. (1994). Continuous Quality Improvement in an Acute Hospital: A Report of an Action Research Project in Three Hospital Departments. International Journal of Health Care Quality Assurance, 7(1), 26.

Powell, T. C. (1995). Total quality management as competitive advantage: A review and empirical study. Strategic Management, 16(1), 15-37.

Rahman, S.-u., \& Bullock, P. (2005). Soft TQM, hard TQM, and organisational performance relationships: an empirical investigation. Omega, 33(1), 11.

Schonberger, R. J. (1994). Human resource management lessons from a decade or total quality management and reengineering. California Management Review, 36(4), 15.

Sila, I. (2007). Examining the effects of contextual factors on TQM and performance through the lens of organizational theories: An empirical study. Journal of Operations Management, 25, 27.

Tang, Z., Chen, X., \& Wu, Z. (2010). Using behavior theory to investigate individual-level determinants of employee involvement in TQM. Total Quality Management, 21(12), 30.

Terziovski, M., \& Power, D. (2007). Increasing ISO 9000 certification benefits: A continuous improvement approach. International Journal of Quality \& Reliability Management, 24, 141-163.

Venkatesh, V., \& Davis, F. D. (1996). A model of the antecedents of perceived ease of use: Development and test. Decision Sciences, 27(3), 31.

Xu, J., \& Quaddus, M. (2007). Exploring the factors Influencing End Users’ Acceptance of Knowledge Management Systems: Development of a Research Model of Adoption and Continued use. Journal of Organizational and End User Computing, 19(4), 23. 